\title{
Enzymatic Synthesis and Curing of Poly(cardanol)
}

\author{
Ryohei IKeda, ${ }^{*}, * *$ Hozumi TANAKa, ${ }^{* *}$ Hiroshi Uyama, ${ }^{* * *}$ \\ and Shiro KOBAYASHI $* * *, * * * *, \dagger$ \\ *Joint Research Center for Precision Polymerization-Japan Chemical Innovation Institute, NIMC, \\ Tsukuba, Ibaraki 305-8565, Japan \\ **Toyo Ink Mfg. Co., Ltd., 27, Wadai, Tsukuba, Ibaraki 300-4247, Japan \\ ***Department of Materials Chemistry, Graduate School of Engineering, \\ Kyoto University, Kyoto 606-8501, Japan \\ ****National Institute of Materials and Chemical Research (NIMC), \\ Tsukuba, Ibaraki 305-8565, Japan
}

(Received January 13, 2000)

\begin{abstract}
Enzymatic polymerization of cardanol, a phenol derivative mainly having a C 15 unsaturated hydrocarbon chain with 1-3 double bonds at $m$-position, and curing of the resulting polymer have been examined. Soybean peroxidase catalyzed the oxidative polymerization of cardanol to give an oily, soluble polymer under appropriate reaction conditions. NMR and IR analysis of the product showed that only the phenolic moiety was polymerized and the carboncarbon unsaturated group in the side chain of cardanol was not reacted during the polymerization. The polymer was subjected to the hardening by cobalt naphthenate catalyst, giving a crosslinked tough film. The curing process was monitored by FT-IR spectroscopy.

KEY WORDS Enzymatic Polymerization / Cardanol / Oxidative Polymerization / Peroxidase / Curing / Coating Material/
\end{abstract}

Recently, there has been strong demand on development of polymeric materials from renewable resources for contribution of global sustainability without depletion of scarce resources. Cardanol (1), a main component obtained by thermal treatment of cashew nut shell liquid (CNSL), is a phenol derivative mainly having the meta substituent of a $\mathrm{C} 15$ unsaturated hydrocarbon chain mainly with 1-3 double bonds. ${ }^{1-3}$ Since CNSL is nearly the one third of the total nut weight, much amount of CNSL is formed as by-product from mechanical processes for the edible use of the cashew kernel. Only a small part of $\mathbf{1}$ obtained in the production of cashew kernel is used in industrial field, though it has potential industrial utilizations in various ways such as resins, friction lining materials, and surface coatings. ${ }^{2,3}$ Therefore, new applications of $\mathbf{1}$ are strongly expected to be developed.

Polymerizations catalyzed by enzymes (enzymatic polymerizations) have received much attention as new methodology of polymer syntheses. ${ }^{4-8}$ Characteristics of enzyme catalysis are expected to provide new polymeric materials, which are difficult to be obtained by conventional methods. Peroxidases induced the oxidative polymerization of phenol derivatives under mild reaction conditions to produce a new class of polyphenols in good yields. ${ }^{9-17}$ This process does not use toxic formaldehyde and their synthetic procedure is very facile. In the peroxidase-catalyzed polymerization of a phenol derivative having a methacryloyl group, the phenolic moiety was chemoselectively polymerized to give a polymer having the methacryloyl group in the side chain. ${ }^{18}$ The polymerization of 3,5-dimethoxy-4-hydroxybenzoic acid (syringic acid) involved the elimination of hydrogen and carbon dioxide from the monomer to give poly $(1,4-$ oxyphenylene) having a carboxylic acid group at one end and a phenolic group at the other. ${ }^{19,20}$ Interestingly, con-

${ }^{\dagger}$ To whom correspondence should be addressed. ventional chemical oxidation catalysts did not induce the polymerization of syringic acid.

Iron- $N, N^{\prime}$-ethylenebis(salicylideneamine) (Fe-salen) showed high catalytic activity toward an oxidative polymerization of 2,6-dimethylphenol and $p$ - $t$-butylphenol, yielding the soluble polymers. ${ }^{21,22}$ We have preliminarily reported that $\mathrm{Fe}$-salen catalyzed the polymerization of cardanol to give the polyphenol containing unsaturated alkyl groups in the side chain, which was cured by cobalt naphthenate catalyst or thermal treatment, yielding the crosslinked polymeric film with high gloss surface. ${ }^{23}$

The enzymatic oxidative polymerization of the hydrogenated cardanol derivatives was reported, ${ }^{24}$ whereas there has been no detailed study on the enzymatic polymerization of 1 and the curing behavior of enzymatically synthesized poly(cardanol) (2). This study deals with the peroxidase-catalyzed polymerization of cardanol (1) and curing of the resulting polymer (Scheme 1).

\section{RESULTS AND DISCUSSION}

\section{Enzymatic Polymerization of Cardanol}

Polymerization results are summarized in Table I. At first, the polymerization of 1 was performed using $10 \mathrm{mg}$ of soybean peroxidase (SBP) as catalyst in an equivol-
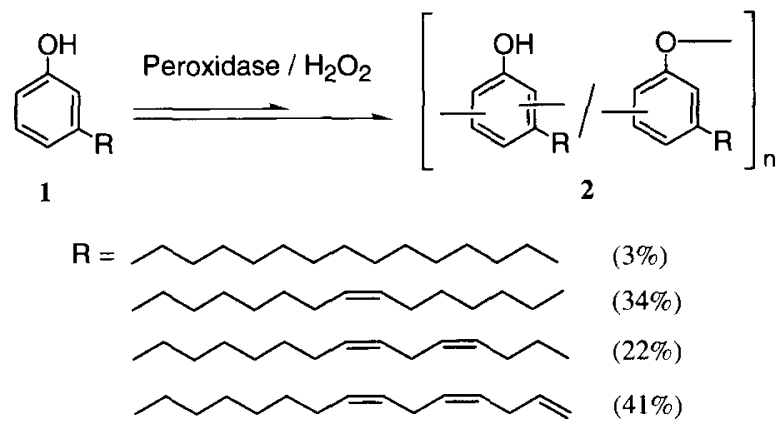

Scheme 1. 
Table I. Enzymatic polymerization of cardanol (1) ${ }^{\text {a }}$

\begin{tabular}{|c|c|c|c|c|c|c|c|}
\hline \multirow{3}{*}{ Entry } & \multirow{3}{*}{$\frac{\text { Monomer }}{\mathrm{mmol}}$} & \multirow{3}{*}{ Solvent ${ }^{\mathrm{b}}$} & \multirow{3}{*}{ Catalyst $^{c}$} & \multicolumn{3}{|c|}{ Soluble polymer } & \multirow{3}{*}{$\begin{array}{c}\text { Insoluble polymer } \\
\frac{\text { Yield }}{\%} \\
\end{array}$} \\
\hline & & & & Yield & $M_{n}^{\mathrm{d}}$ & $M_{w} / M_{n}^{\mathrm{d}}$ & \\
\hline & & & & $\%$ & $\times 10^{3}$ & & \\
\hline 1 & 5.0 & Acetone/pH 7.0 Phosphate buffer $(75: 25)$ & SBP $(20)$ & 21 & 4.8 & 1.7 & 19 \\
\hline 2 & 5.0 & Acetone/pH 7.0 Phosphate buffer $(75: 25)$ & $\operatorname{HRP}(20)$ & 0 & & & 0 \\
\hline 3 & 5.0 & 1,4-Dioxane/pH 7.0 Phosphate buffer $(85: 15)$ & SBP $(20)$ & 0 & & & 0 \\
\hline 4 & 2.0 & Isopropanol/pH 7.0 Phosphate buffer $(50: 50)$ & SBP (10) & 69 & 6.1 & 1.8 & 0 \\
\hline 5 & 2.0 & Isopropanol/pH 7.0 Phosphate buffer $(50: 50)$ & $\operatorname{SBP}(50)$ & 0 & & & 100 \\
\hline 6 & 2.0 & Isopropanol/pH 7.0 Phosphate buffer $(70: 30)$ & $\operatorname{SBP}(10)$ & 0 & & & 35 \\
\hline 7 & 2.0 & Isopropanol/distilled water $(50: 50)$ & SBP $(10)$ & 38 & 10.0 & 4.6 & 33 \\
\hline
\end{tabular}

${ }^{a}$ Polymerization of cardanol $(0.60 \mathrm{~g})$ using peroxidase catalyst in an aqueous organic solvent $(25 \mathrm{~mL})$ at room temperature under air. ${ }^{\mathrm{b}}$ In parenthesis, mixed ratio of solvents (vol\%). "In parenthesis, enzyme amount (mg). ${ }^{\mathrm{c}}$ Determined by SEC.

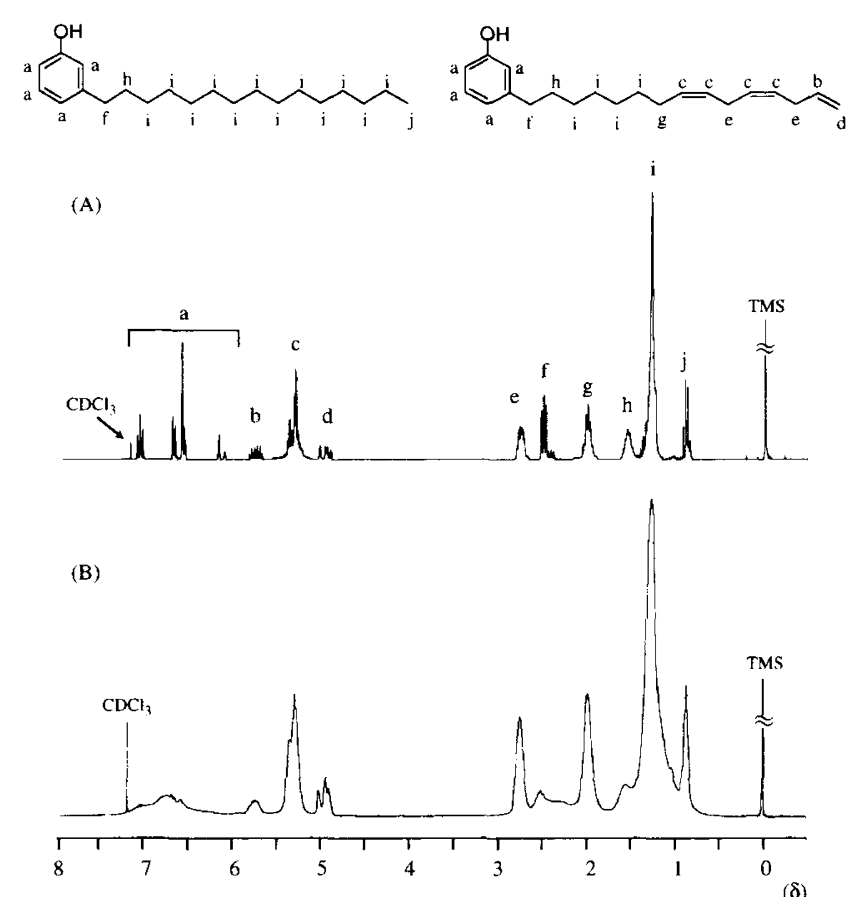

Figure 1. ${ }^{1} \mathrm{H}$ NMR spectra of (A) cardanol (1) and (B) poly(cardanol) (2) (entry 4 in Table I).

ume mixture of isopropanol and $\mathrm{pH} 7$ phosphate buffer at room temperature for $24 \mathrm{~h}$ under air (entry 4). Hydrogen peroxide was used as oxidizing agent. During the polymerization, oily polymeric materials were formed. The polymer was purified by reprecipitation using ethyl acetate (good solvent) and methanol (poor solvent). Isolated poly(cardanol) (2) was viscous, dark yellow oil. The isolated yield was $69 \%$ and its molecular weight and index, determined by size exclusion chromatography (SEC), were $6.1 \times 10^{3}$ and 1.8 , respectively. The polymer was soluble in chloroform, $N, N$-dimethylformamide (DMF), and ethyl acetate, and insoluble in acetone, methanol, and water.

Polymer structure was confirmed by ${ }^{1} \mathrm{H}$ NMR and IR spectroscopies. Figure 1 shows ${ }^{1} \mathrm{H}$ NMR spectra of 1 and 2. Peaks' assignment of $\mathbf{1}$ (typically, isomers having no and three unsaturated groups) is shown in Figure 1(A). All the peaks of 2 became broader than those of 1 . The integrated area ratio of peaks due to unsaturated and saturated groups in the side chain did not change before and after the polymerization, indicating that the unsaturated group was not reacted and only the phenolic moiety was polymerized during the polymerization. FT-IR spectrum of 1 (Figure 2(A)) shows a characteristic peak

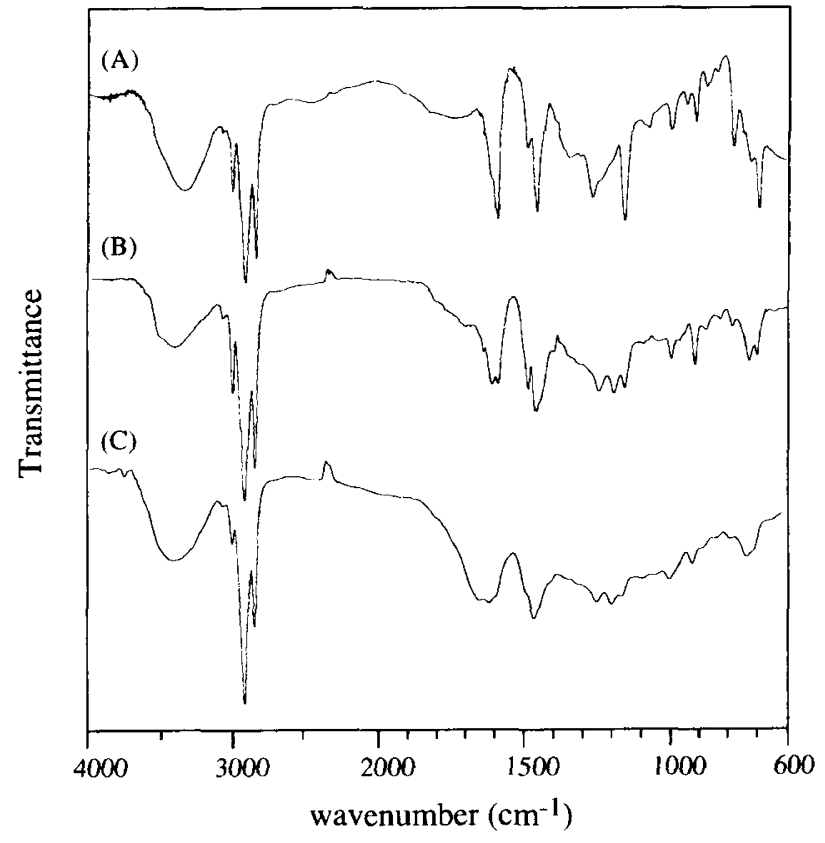

Figure 2. FT-IR spectra of (A) cardanol (1), (B) soluble poly(cardanol) (2) (entry 4 in Table I), and (C) insoluble poly(cardanol) (2) (entry 5 in Table I).

at $3010 \mathrm{~cm}^{-1}$ due to $\mathrm{C}-\mathrm{H}$ vibration of the unsaturated hydrocarbon moiety. In the FT-IR spectrum of 2 (Figure $2(\mathrm{~B})$ ), this peak remained almost unchanged, supporting no reaction of the unsaturated group during the polymerization.

Peaks of 2 at $3400 \mathrm{~cm}^{-1}$ due to the vibration of $\mathrm{O}-\mathrm{H}$ linkage of phenolic group and at 780 and $694 \mathrm{~cm}^{-1}$ ascribed to $\mathrm{C}-\mathrm{H}$ deformation vibrations of 1,3 -disubstituted benzenes became smaller than those of 1 . Observed were three characteristic peaks at 1242, 1190 , and $1151 \mathrm{~cm}^{-1}$ ascribed to the vibrations of the $\mathrm{C}-\mathrm{O}-\mathrm{C}$ and/or $\mathrm{C}-\mathrm{OH}$ linkages. These data indicate that poly (cardanol) (2) consisted of a mixture of phenylene and oxyphenylene units. The similar structure was observed in the oxidative polymerization of 1 catalyzed by $\mathrm{Fe}$-salen ${ }^{23}$ and peroxidase-catalyzed polymerization of $m$-substituted phenols. $^{25}$

In the polymerization using $50 \mathrm{mg}$ of SBP under the similar reaction conditions, the powdery polymer was quantitatively obtained (entry 5). However, the polymer was insoluble in organic solvents. In the FT-IR spectrum of the insoluble polymer (Figure $2(\mathrm{C})$ ), the peak at 3010 $\mathrm{cm}^{-1}$ ascribed to the unsaturated hydrocarbon group became smaller than that of soluble 2 . These data indicate 
Table II. Pencil scratch hardness of cured product from cardanol (1) and poly (cardanol) (2)

\begin{tabular}{|c|c|c|c|c|c|c|c|c|}
\hline \multirow[b]{2}{*}{ Sample } & \multirow[b]{2}{*}{ Catalyst $^{\mathrm{a}}$} & \multicolumn{7}{|c|}{ Time } \\
\hline & & $2 \mathrm{~h}$ & $1 \mathrm{~d}$ & $3 \mathrm{~d}$ & $6 \mathrm{~d}$ & $9 \mathrm{~d}$ & $14 \mathrm{~d}$ & $18 \mathrm{~d}$ \\
\hline 1 & None & - & - & - & - & - & - & - \\
\hline 1 & Cobalt naphthenate(3.0) & - & - & - & - & Set to touch & $<6 \mathrm{~B}$ & $<6 \mathrm{~B}$ \\
\hline $\mathbf{2}^{\mathrm{b}}$ & None & - & - & - & 一 & Set to touch & $<6 \mathrm{~B}$ & $<6 \mathrm{~B}$ \\
\hline $\mathbf{2}^{\mathrm{b}}$ & Cobalt naphthenate(3.0) & Set to touch & $<6 \mathrm{~B}$ & $5 \mathrm{~B}$ & HB & $\mathrm{HB}$ & $\mathrm{H}$ & $\mathrm{H}$ \\
\hline
\end{tabular}

${ }^{\mathrm{a}}$ In parenthesis, catalyst amount for samples (wt\%). ${ }^{\mathrm{b}}$ Sample: soluble 2 of entry 1 in Table I.

that the unsaturated group as well as the phenolic moiety were reacted in the presence of larger amount of SBP catalyst, resulting in the formation of the crosslinked insoluble product.

When an aqueous 1,4-dioxane was used as solvent (entry 3 ), the polymer was not formed. The SBP-catalyzed polymerization in a mixture of isopropanol and the buffer $(70: 30 \mathrm{vol} \%)$ produced the insoluble powdery product, despite the small amount of the enzyme (entry 6 ). Instead of the buffer, distilled was used as cosolvent, yielding a mixture of the oily soluble polymer and powdery insoluble product (entry 7).

Horseradish peroxidase (HRP) can polymerize various phenols, yielding a new class of polyphenols. As to $\mathbf{1}$, however, the HRP-catalyzed polymerization in acetone/ $\mathrm{pH} 7$ phosphate buffer (75/25 vol\%) did not proceed (entry 2). On the other hand, SBP catalysis induced the polymerization under the similar reaction conditions to give 2 (entry 1). Our previous study on the peroxidasecatalyzed polymerization of $m$-substituted phenols showed that HRP could readily polymerize the monomer having a small substituent, whereas in the case of large substituent monomers, the high yield was achieved by using SBP catalyst. ${ }^{25} \mathrm{~A}$ similar tendency was observed in the present study.

\section{Curing of Poly(cardanol)}

Preparation of crosslinked film was examined by curing of 2 (soluble part of entry 1 in Table I) using cobalt naphthenate as catalyst ( 3 wt\% for 2 ). The sample film was prepared on a glass slide and stood under ambient conditions. The curing was monitored by pencil scratch hardness (Table II).

Poly(cardanol) (2) was cured rapidly (after $2 \mathrm{~h}$ ) and the hardness increased with time. Finally, the pencil scratch hardness reached to $\mathrm{H}$, which is enough hard for industrial uses. Cardanol (1) was also cured with the cobalt naphthenate catalyst. However, the curing rate and the hardness of the resulting film were much inferior to those of 2 . These data indicate that 2 was a good precursor for the brilliant film.

In the curing without the catalyst (control experiment), the curing of $\mathbf{2}$ proceeded very slowly to give the much soft film, suggesting that cobalt naphthenate efficiently catalyzed the hardening of $\mathbf{2}$. The monomer was not cured without the catalyst.

The curing behavior was also monitored by FT-IR spectroscopy (Figure 3). A peak at $3010 \mathrm{~cm}^{-1}$ due to the unsaturated group gradually became smaller. Intensity of a peak at $912 \mathrm{~cm}^{-1}$ ascribed to $\mathrm{C}-\mathrm{H}$ vibration of the terminal vinyl group also gradually decreased. On the other hand, a peak at $976 \mathrm{~cm}^{-1}$ due to $\mathrm{C}-\mathrm{H}$ vibration of the nonconjugated trans double bond newly appeared and its intensity increased as a function of time. A peak

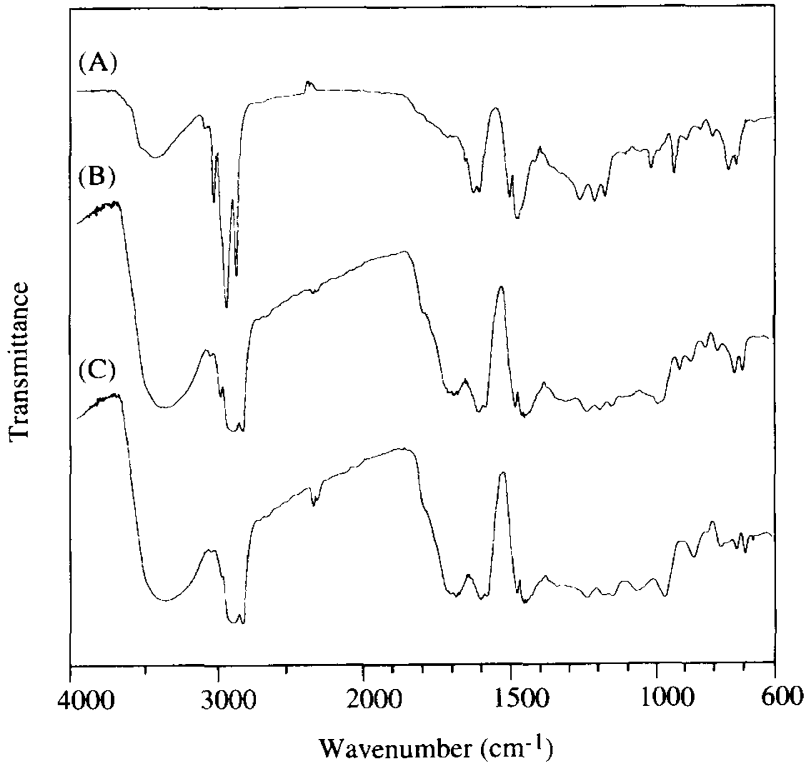

Figure 3. FT-IR spectra of (A) poly(cardanol) (2) (soluble part of entry 1 in Table I), (B) the cured product after 3 days, and (C) that after 6 days.

at $994 \mathrm{~cm}^{-1}$ ascribed to that of the conjugated cis-trans vibration bond was also newly observed after 3 days, however, later disappeared. The appearance of the conjugated cis-trans diene group might be owing to the formation of a radical intermediate by the abstraction of hydrogen atom on methylene group between double bonds. ${ }^{26}$ These data indicate that the isomerization and crosslinking reaction of the unsaturated group took place during the hardening.

Furthermore, a new broad peak at $1680-1720 \mathrm{~cm}^{-1}$ was observed, which might be due to $\mathrm{C}=\mathrm{O}$ vibration of saturated and unsaturated aldehydes and ketones. A broad peak at $3400 \mathrm{~cm}^{-1}$ due to $\mathrm{O}-\mathrm{H}$ vibration became larger. Similar spectral changes were observed in autoxidation of oils containing unsaturated alkyl groups such as soy and linseed oils. ${ }^{26,27}$

Pyrolysis gas chromatography-mass (GC-MS) has been used for structural analysis of phenolic polymers $^{28,29}$ and urushi $^{30}$ (enzymatic cured product of urushiol, a catechol derivative having unsaturated group in the side chain). Figure 4 shows pyrolysis GCMS spectrum of the cured polymer, stood for 8 months under ambient conditions. In the spectrum of $\mathrm{m} / \mathrm{z}=108$, 10 peaks due to aklylphenols with carbon number of the side chain from 1 to 10 were clearly observed, which is supposed to be formed by the cleavage of $\mathrm{C}-\mathrm{O}$ bond. These data support the formation of the oxyphenylene unit by the peroxidase-catalyzed polymerization of $\mathbf{1}$. The largest peak was seen in $\mathrm{C} 7$ alkylphenol, which may be due to the frequent occurrence of the reaction at 


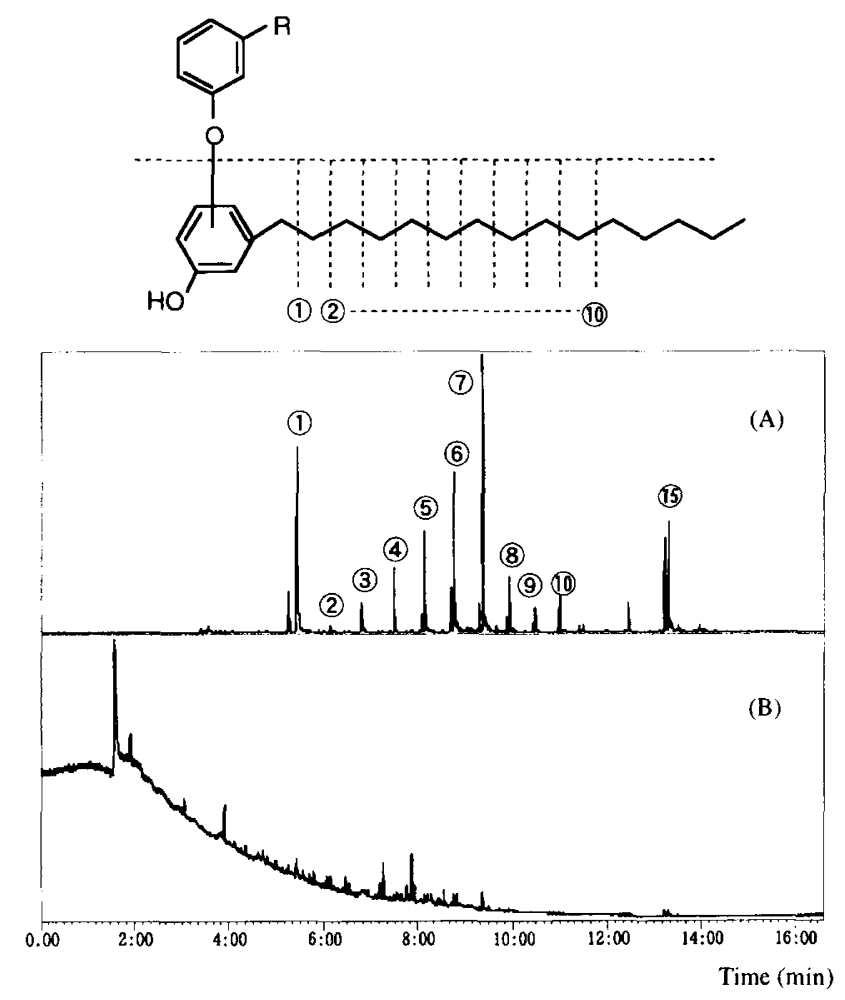

Figure 4. Pyrolysis GC-MS chromatograms of the cured product of (A) $\mathrm{m} / \mathrm{z}=108$ and (B) total ions.

\section{8-C 9 double bond}

\section{CONCLUSION}

Peroxidase-catalyzed oxidative polymerization of cardanol (1) produced a new class of crosslinkable polyphenols having unsaturated alkyl group in the side chain. The curing of the resulting polymer took place rapidly in the presence of cobalt naphthenate to give the brilliant film. The present prepolymer is synthesized from the renewable plant-based material without use of toxic formaldehyde. In the curing stage, the crosslinked polymeric film is obtained in the absence of organic solvents at an ambient temperature under air. Therefore, the present method can be regarded as an environmentally benign process of polymer coating, providing an example system of green polymer chemistry. Further investigations on the production of crosslinkable polymers from renewable resources are under way in our laboratory.

\section{EXPERIMENTAL}

\section{Materials}

Cardanol of technical grade was provided by Tohoku Kako Co. and used without further purifications. HRP and SBP were purchased from Wako Pure Chemical and Sigma, respectively. Other reagents were commercially available and used as received.

\section{Enzymatic Polymerization of Cardanol}

A typical run was as follows (entry 4 in Table I). Under air, $0.60 \mathrm{~g}(2.0 \mathrm{mmol})$ of cardanol and $20 \mathrm{mg}$ of SBP in $12.5 \mathrm{~mL}$ of isopropanol and $12.5 \mathrm{~mL}$ of $\mathrm{pH} 7$ phosphate buffer were placed in a $50 \mathrm{~mL}$ of flask. Hydrogen peroxide ( $6 \%$ aqueous solution, $1.5 \mathrm{~mL}, 2.0 \mathrm{mmol}$ ) was added dropwise to the mixture for $6 \mathrm{~h}$ at room temperature under gentle stirring. After $24 \mathrm{~h}$, the reaction mixture was concentrated under reduced pressure. Ethyl acetate $(20 \mathrm{~mL})$ was added to the residue and the organic layer was separated, following by the removal of the solvent under reduced pressure. The oily residue was poured into a large amount of cold methanol. The methanol-insoluble part was separated by centrifugation and dried in vacuo to give $0.41 \mathrm{~g}$ of the polymer (yield $69 \%$ ).

\section{Measurements}

Size exclusion chromatographic (SEC) analysis was carried out using a Tosoh SC 8020 apparatus with a refractive index (RI) detector under the following conditions: TSKgel GMHHR-M and GMHHR-L columns and DMF eluent containing $0.4 \mathrm{wt} \%$ lithium chloride at a flow rate of $1.0 \mathrm{~mL} \mathrm{~min}{ }^{-1}$. The calibration curves for SEC analysis were obtained using polystyrene standards. ${ }^{1} \mathrm{H}$ NMR and IR spectra were recorded on a 300 $\mathrm{MHz}$ Varian BB 300 and Perkin-Elmer Paragon 1000 spectrometers, respectively. Pencil scratch hardness was evaluated according to the literature. ${ }^{31}$ Pyrolysis GC-MS measurement was carried out using a Frotier Lab PY2010 D vertical micro furnace-type pyrolyzer, a HewlettPackard HP 6890 gas chromatograph and a JEOL Automass II spectrometer. The pyrolysis was carried out at $500^{\circ} \mathrm{C}$. The GC analysis was performed using a Fontier Lab PY-1 column in keeping at $40^{\circ} \mathrm{C}$ for $1 \mathrm{~h}$ and subsequent heating at $20^{\circ} \mathrm{C} \min ^{-1}$ rate to $330^{\circ} \mathrm{C}$.

Acknowledgments. This work was partly supported by NEDO for the project on Technology for Novel HighFunctional Materials in Industrial Science and Technology Frontier Program, AIST and a Grant-in-Aid for Specially Promoted Research (No. 08102002) from the Ministry of Education, Science, Sports and Culture, Japan.

\section{REFERENCES AND NOTES}

1. O. A. Attanasi, S. Buratti, and P. Filippone, Chim. Ind., 78, 693 (1996)

2. A. R. R. Menon, C. K. S. Pillai, J. D. Sudha, and A. G. Mathew, J. Sci. Ind. Res., 44, 324 (1985).

3. P. H. Gedam and P. S. Sampathkumaran, Prog. Org. Coat., 14, 115 (1986).

4. S. Kobayashi, J. Polym. Sci., Polym. Chem. Ed., 37, 3041 (1999).

5. S. Kobayashi, S. Shoda, and H. Uyama, "The Polymeric Materials Encyclopedia”, J. C. Salamone, Ed., CRC Press, Boca Raton, FL, pp 2102-2107, 1996.

6. S. Kobayashi, S. Shoda, and H. Uyama, "Catalysis in Precision Polymerization", S. Kobayashi, Ed., John Wiley \& Sons, Chichester, Chapter 8, 1997.

7. R. A. Gross, D. L. Kaplan, and G. Swift, Ed., "ACS Symp. Ser"., Vol. 684, 1998.

8. H. Uyama and S. Kobayashi, CHEMTECH, 29(10), 22 (1999).

9. J. S. Dordick, M. A. Marletta, and A. M. Klibanov, Biotechnol. Bioeng., 30, 31 (1987).

10. J. A. Akkara, K. J. Senecal, and D. L. Kaplan, J. Polym. Sci., Polym. Chem. Ed., 29, 1561 (1991).

11. H. Uyama, H. Kurioka, I. Kaneko, and S. Kobayashi, Chem. Lett., 423 (1994).

12. P. Wang, B. D. Martin, S. Parida, D. G. Rethwisch, and J. S. Dordick, J. Am. Chem. Soc., 117, 12885 (1995).

13. S. Kobayashi, H. Uyama, and H. Kurioka, Macromol. Rapid 
Commun., 17, 503 (1996).

14. R. Ikeda, J. Sugihara, H. Uyama, and S. Kobayashi, Macromolecules, 29, 8702 (1996).

15. M. Ayyagari, J. A. Akkara, and D. L. Kaplan, Acta Polymerica, 47, 193 (1996).

16. S. Kobayashi, H. Uyama, T. Ushiwata, T. Uchiyama, J. Sugihara, and H. Kurioka, Macromol. Chem. Phys., 199, 777 (1998).

17. T. Oguchi, S. Tawaki, H. Uyama, and S. Kobayashi, Macromol. Rapid Commun., 20, 401 (1999).

18. H. Uyama, C. Lohavisavapanich, R. Ikeda, and S. Kobayashi, Macromolecules, 31, 554 (1998).

19. R. Ikeda, H. Uyama, and S. Kobayashi, Macromolecules, 29, 3053 (1996).

20. R. Ikeda, J. Sugihara, H. Uyama, and S. Kobayashi, Polym. Int., 47, 295 (1998).

21. H. Tonami, H. Uyama, S. Kobayashi, S. Higashimura, and T. Oguchi, J. Macromol. Sci.-Pure Appl. Chem., A 36, 719 (1999).

22. H. Tonami, H. Uyama, T. Oguchi, H. Higashimura, and S. Kobayashi, Polym. Bull., 42, 125 (1999).
23. R. Ikeda, H. Tanaka, H. Uyama, and S. Kobayashi, Macro mol. Rapid Commun., in press.

24. K. S. Alva, P. L. Nayak, J. Kumar, and S. K. Tripathy, J. Macromol. Sci.-Pure Appl. Chem., A 34, 665 (1997)

25. H. Tonami, H. Uyama, S. Kobayashi, and M. Kubota, Macromol. Chem. Phys., 200, 2365 (1999).

26. Z. W. Wicks, Jr., F. N. Jones, and S. Peter Pappas, "Organic Coatings: Science and Technology, Vol. 1: Film Formation, Components, and Appearance", John Wiley \& Sons, New York, N.Y., Chapter 9, 1992.

27. A. Gandini and M. N. Belgacem, "The Polymeric Materials Encyclopedia", J. C. Salamone, Ed., CRC Press, Boca Raton, FL., pp 8530-8541, 1996.

28. T. P. Wampler, G. A. Bishea, and W. J. Simonsick, J. Anal. Appl. Pyrolysis, 40-41, 79 (1997).

29. M. Blazso, J. Anal. Appl. Pyrolysis, 19, 251 (1991).

30. N. Niimura, T. Miyakoshi, J. Onodera, and T. Higuchi, J. Anal. Appl. Pyrolysis, 37, 199 (1996).

31. P. R. Guevin, Jr., J. Coat. Technol., 67, 61 (1995). 